\title{
Examination on Lightweight Banana Fibre (bunch) and Polyestercomposite for Industrial Applications
}

\author{
Muthukannan M, Chithambar Ganesh A, Mukilan K
}

\begin{abstract}
The durability of non-natural-reusable polymers is less identified, and it is challenging to dispose. To increase the durability and solve the disposal problem, polymers are reinforced with fibers. In this study, the banana fiber is used to prepare a lightweight composite mixed with a polymer compound. The fiber is extracted from the bunch of banana by retting process. The fabrication was done by adding fiber and the polyester resin in the mould by varying the composition, and the length of the fiber was fixed as $40 \mathrm{~mm}$. As per standard of ASTM, The impact, tensile and flexural strength tests were conducted for the fabricated composite. The result was compared with coconut fiber and polyester resin composite. The study shows that the fiber prepared with the banana bunch shows a remarkable increase in mechanical properties proves to be a light weight material because of its less dense of fiber as $581 \mathrm{~kg} / \mathrm{m} 3$. Hence, for industrial applications, the composite made of banana fiber and polyester can be used.
\end{abstract}

Keywords:Banana Fiber; Coconut Fiber; Polyester; Composite; Mechanical Properties.

\section{INTRODUCTION}

$\boldsymbol{F}_{\text {or the past few years, attention was increased on }}$ natural fibers in composites due to its plenty advantageous like impact on environmental, disposal problems, good impact on mechanical properties and it's less dense. According to strength and stiffness, the fibers of naturally available can better in perform than glass fibers. To overcome the brittleness, stiffness and hard polymer, material combination as that of the composite were needed. Replacement of conventional materials like wood and metals were done by the composite after completing the challenges because of its less weight, high strength and stiffness. The researchers had attention on reducing the raw material's cost by composite with natural fibre reinforce utilizing banana, sisal, coir, pineapple and jute.

Grisha et al. have investigated the behaviour of composite materials reinforced with ridge gourd, sisal and coconut spade as natural fiber and mixed with epoxy resin in tensile. The fibers extraction were done by the process of retting and treated with alkalies. The increment in tensile behaviour was observed when increment in weight of fibres up to a certain limit, after that decrement in behaviour took place. The composite materials hybridization shows greater tensile strength in the mix of sisal and ridge guard fibers at

Revised Manuscript Received on July 22, 2019

* Correspondence Author

Muthukannan $\mathbf{M}^{*}$, Department of Civil Engineering, Kalasalingam Academy of Research and Education, Virudhunagar, India. Email: civilkannan@gmail.com

Chithambar Ganesh A, Department of Civil Engineering, Kalasalingam Academy of Research and Education, Virudhunagar, India. Email: chithambarmailid@gmail.com

Mukilan K, Department of Civil Engineering, Kalasalingam Academy of Research and Education, Virudhunagar, India. Email: k.mukilan@klu.ac.in
65 percentages.Ratna Prasad et al. have investigated the mechanical behaviour of polymer composites reinforced with banana fruit fibre. Utilization of the polyester resins was as a matrix and fiber with different particle size and weight percentages. They found that the fiber composites show considerable work of fracture., Ashok Kumar et al. (2011), Singha et al. (2008), Munikenche et al. (1999) have used other natural materials such as Hibiscus sabdariffa, SansevieraTrifasciata, jute fiber, rice husk, saw dust for making the polymer composite. In all the studies, it could be observed that polymers like rubber and epoxy are widely used. The results of the studies also show that the natural fibers perform well in withstanding the impact energy, tensile force and flexural strength.

Due to their application of space vehicle technology and aerospace, the performance of composite made with silicon or boron carbide fiber, kevlar, glass and graphite had been studied (Ramesh et al., 2013, Mikata, 1985 Nak-ho et al., 1979 and Zhou, 2009). The requirement of our latest technologies was material with a combination of properties which couldn't get by the traditional metal, ceramic and polymeric substances Hameed Sahib et al. (2015). This mainly real for materials which might be needed for automotive, aerospace and other transportation applications which have low density, stiff and abrasion resistant and impact resistant.

Hence in this study, a polymer composite consists of natural fiber banana bunch and epoxy resins are used. The fractions in the Fiber Reinforced Polymer (FRP) composites are varied to get the maximum tensile, flexural and impact strength. The fabrication is done with a mould and kept in the compression machine. Fabricated specimens are cut into $40 \mathrm{~mm}$ length of different fiber fractions and tested. The results of the test show that the behaviour in tensile, flexure and impact of Banana Fiber Reinforced Composites (BFRC) is good when compared to the Coconut Fiber Reinforced Composites (CFRC) studied previously.

\section{MATERIALS}

\section{A. Banana Fiber}

Banana Plant is cultivated in Asian countries. The banana fruit is edible, and stem, leaf and the empty fruit bunch consist of fibers. The banana fibers are having excellent mechanical properties. The composites made using banana fiber are used as engineering materials, and it replaces glass fiber. Banana empty fruit bunch (banana EFB) fibers were obtained from M/s KodaliArjuna Rao \&Co., India. The fibers were extracted using decorticating machine. The fibers have a diameter of $0.015-0.12 \mathrm{~mm}$, length of $40 \mathrm{~mm}$, tensile strength of $62.40 \mathrm{MPa}$, modulus of $2.0 \mathrm{GPa}$ and elongationat break of $3.10 \%$. 


\section{B. Catalyst (Methyl Ethyl Ketone Peroxide)}

MEKP is organic peroxide; Likewise acetone peroxide, it's a high explosive. It is soluble in four times of water. MEKP is colourless oily liquid whereas acetone peroxide is a white powder. MEKP is extra strong in storage and slightly sensitive to shock and temperature. Boling and melting point is $85.9 \& 79.6$ degree Celsius.

\section{Accelerator}

Cobalt Naphthenate is used to activate the process and to accelerate the resin at room temperature at a more significant rate. They are widely employed as catalyst because they are soluble in the non-polar substrates, such as alkyd resins or linseed oil as the Naphthanate mixtures help to confer high solubility and it is low cost and contains manganese and iron.

\section{Reactions between Catalyst, Accelerator and Resin}

In the polymer, catalyst or initiators are the most important additive. Typically, for room temperature cured process organic peroxide such as MEKP is used and heat cured moulding benzoyl peroxide is added to the resin. Peroxides convert to reactive state (exhibiting free radicals) causing the unsaturated resins to react and become solid when triggered by heat, or used in conjunction with a promoter (such as cobalt Napthanate).

\section{FABRICATION AND CURING}

Banana bunch fiber is taken as small pieces of $40 \mathrm{~mm}$ length and according to the weight ration 20, 30, 40, and 50 percentages by weight are arranged into the mould. About $150 \mathrm{ml}$ resin and $1.5 \mathrm{ml}$ accelerator catalyst is used for fabricating the composites. Compression molding technique is used in this study. Before the compression molding technique, the release agent was applied to the mould to avoid hold of some part in the mould. The banana fiber was laid in the mould after cut into small pieces. The resin is catalyzed and added to the fibers and then fibers are impregnated into resin with the help of a brush, rollers. By mixing the catalyst which creates chemical reaction without modifying its composition, Thermoset resins like polyester are cured. The catalyst helps to initiate the chemical reaction of the unsaturated polyester and monomer ingredient from the state of liquid to solid. In order of the fibers and matrix, lower shrinkage is desirable after curing.

\section{TESTING OF FIBER REINFORCED POLYMER COMPOSITES}

\section{A. Tensile Strength Test}

The behaviour in tensile of Fiber Reinforced Composite (FRC) is improved on the addition of fibers because of fiber's higher stiffness and strength. The performance of FRC is increased by fibers. Hence the effect of tensile properties of FRC is of particular interest and significance for many researchers Ahmad et al. (2006). In this study, the tensile property of BFRC is studied and compared with CFRC. According to ASTMD3039, (Instron Series-3382) a universal testing machine was used to measure the tensile behaviour of the composites and it has a $\max$ capacity of $100 \mathrm{KN}$ load \& $0.05 \mathrm{~mm} / \mathrm{min}$ to 500 $\mathrm{mm} / \mathrm{min}$ speed range. The gauge length was $100 \mathrm{~mm}$ and the crosshead speed of $5 \mathrm{~mm} / \mathrm{min}$ was maintained. The sample of 12 numbers with the dimension of $200 \times 20 \times 3 \mathrm{~mm}$ was used for testing. The tensile modulus was calculated by diving tensile stress and tensile strain. Tensile strain was measured by fixing the strain gauges.

The tensile strength results of BFRC and CFRC are as shown in Table 1, Fig.1 and Fig.4. The tensile strength of BFRC increased at 30 percent of fiber, and started to decline beyond 40 percentages. The maximum tensile strength of BFRC was $23.80 \mathrm{Mpa}$, and CFRC recorded as $23.68 \mathrm{Mpa}$ There was no much variation in tensile property of BFRC and CFRC.

Table- I: Tensile Strength of Banana fiber and Coconut Fiber

\begin{tabular}{|l|l|l|l|l|l|}
\hline S.No & \multirow{2}{*}{$\begin{array}{l}\text { Percentage } \\
\text { by Weight }\end{array}$} & \multicolumn{2}{|l|}{$\begin{array}{l}\text { Tensile Strength } \\
\text { (Mpa) }\end{array}$} & \multicolumn{2}{l|}{$\begin{array}{l}\text { Tensile } \\
\text { (Mpa) }\end{array}$} \\
\cline { 3 - 6 } & & $\begin{array}{l}\text { Banana } \\
\text { Fiber }\end{array}$ & $\begin{array}{l}\text { Coconut } \\
\text { Fiber }\end{array}$ & $\begin{array}{l}\text { Banana } \\
\text { Fiber }\end{array}$ & $\begin{array}{l}\text { Coconut } \\
\text { Fiber }\end{array}$ \\
\hline 1 & 20 & 23.42 & 23.03 & 1122.30 & 977.80 \\
\hline 2 & 30 & 23.80 & 23.68 & 1154.10 & 1000.00 \\
\hline 3 & 40 & 23.78 & 21.05 & 1236.10 & 1066.63 \\
\hline 4 & 50 & 21.65 & 18.42 & 2001.47 & 1733.30 \\
\hline
\end{tabular}

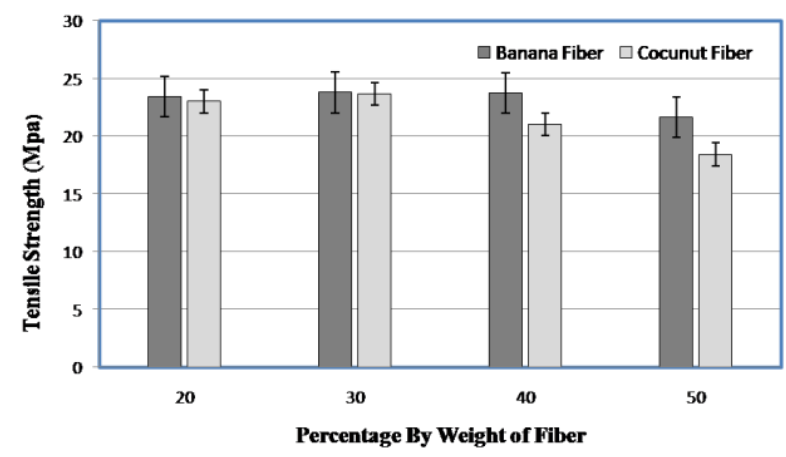

Fig. 1: Tensile Strength of Banana Fiber and Coconut Fiber

\section{B. Flexural Strength Test}

The flexural strength or modulus of rupture is the property of the material as the stress in a material just before it yields in a flexure test. If the material is homogeneous the tensile strength will be equal to the modulus of rupture. Increment in flexural strength will observe due to fibers addition. Hence, it is important to know the flexural property of the BFRC and CFRC. In this study, the behaviour of materials in a simple beam loading condition was studied by flexure test. For an increment of load, maximum fiber stress and strain are measured. ASTM D790 is the standard referred for the conduction of the three-point bending stress. The span length of $50 \mathrm{~mm}$ for three-point bending was determined to this standard. The 12 samples with the dimensions of $127 \times 12 \times 3 \mathrm{~mm}$ were tested.

The results of the flexural strength of BFRC and CFRC are as shown in Table 2, Fig.2 and Fig.4. The flexural strength of BFRC and CFRC up to 30 percent by weight performed similar, and at 40 percentages BFRC started to perform well, and maximum flexural strength obtained by BFRC was 47.0 Mpa which was 30.85 percent higher than the CFRC. 
Table- II: Flexural Strength of Banana fiber and Coconut Fiber

\begin{tabular}{|l|l|l|l|l|l|}
\hline \multirow{2}{*}{ S.No } & \multirow{2}{*}{$\begin{array}{l}\text { Percentage } \\
\text { by Weight }\end{array}$} & \multicolumn{2}{|l|}{$\begin{array}{l}\text { Flexural Strength } \\
\text { (Mpa) }\end{array}$} & $\begin{array}{l}\text { Flexural Modulus } \\
\text { (Mpa) }\end{array}$ \\
\cline { 3 - 6 } & $\begin{array}{l}\text { Banana } \\
\text { Fiber }\end{array}$ & $\begin{array}{l}\text { Coconut } \\
\text { Fiber }\end{array}$ & $\begin{array}{l}\text { Banana } \\
\text { Fiber }\end{array}$ & $\begin{array}{l}\text { Coconut } \\
\text { Fiber }\end{array}$ \\
\hline 1 & 20 & 24.8 & 22.4 & 944.7 & 898.5 \\
\hline 2 & 30 & 29.6 & 29.3 & 1567.6 & 1520.5 \\
\hline 3 & 40 & 38.8 & 31.02 & 1746.5 & 1620.4 \\
\hline 4 & 50 & 47.0 & 32.5 & 2461.4 & 1846.2 \\
\hline
\end{tabular}
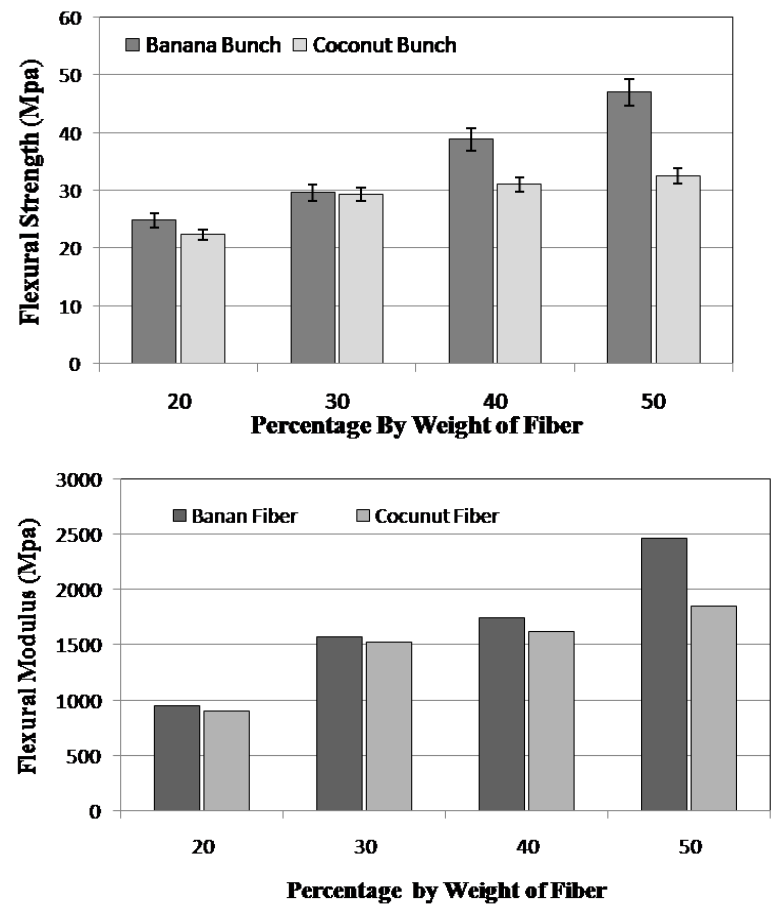

Fig. 2:Flexural Strength of Banana Fiber and Coconut Fiber

\section{Impact Strength Test}

Information about the requirement of energy to break the specimen, magnitude and ability to resist sudden impact were given by the impact strength of the material Elanchezhian et al. (2018). The resistance to impact depends on the physical properties of material, polymers and matrix of fiber, Satyanarayana et al. (1986). In this study, the ability of BFRC and CFRC resist the impact was studied by Izod impact test. According to ASTM D $256 \mathrm{M}$ to measure the impact strength, Izod impact test specimens of size $65 \times 13 \times 10 \mathrm{~mm}$ were prepared. To obtain a consistent starter crack, a sharp file was drawn across the center of the cut at 90 degrees to the sample axis with an included angle of 45 degrees. The sample of 12 numbers were tested in a plastic impact testingmachine and from the absorbed energy \& sample width, the impact strength was determined.

Table 3, Fig 3 and Fig.4 show the Izod test results of BFRC and CFRC for various Percentages by weight of fibers. The impact test of BFRC and CFRC showed that up to 30 percent of fiber to weight BFRC and CFRC had the similar resistance, at 40 percentages BFRC started to resist more energy, which was $10.25 \mathrm{KJ} / \mathrm{m}^{2}$ against $\mathrm{CFRC}$ as 9.1 $\mathrm{KJ} / \mathrm{m}^{2}$. The testing result showed that BFRC resisted more sudden impact at 50 Percentages by weight of fibers of 14.17 $\mathrm{KJ} / \mathrm{m}^{2}$ which was 27.66 percentages higher than the CFRC $\mathrm{BFRC}$ resisted more impact energy than CFRC.
Table- III: Impact Strength of Banana fiber and Coconut Fiber

\begin{tabular}{|l|l|l|l|}
\hline S.No & \multirow{2}{*}{$\begin{array}{c}\text { Percentage } \\
\text { by Weight }\end{array}$} & \multicolumn{2}{|l|}{ Impact Strength $\mathbf{K J} / \mathbf{m}^{2}$} \\
\cline { 3 - 4 } & & Banana Fiber & Coconut Fiber \\
\hline 1 & 20 & 7.05 & 7.02 \\
\hline 2 & 30 & 7.84 & 7.74 \\
\hline 3 & 40 & 10.25 & 9.1 \\
\hline 4 & 50 & 14.17 & 10.25 \\
\hline
\end{tabular}

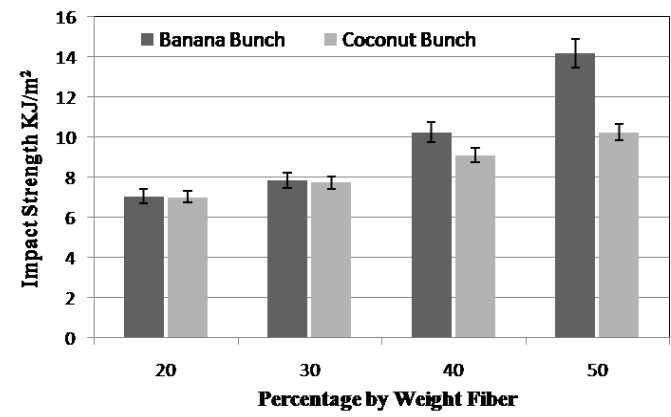

Fig. 3:Impact Strength of Banana Fiber and Coconut Fiber

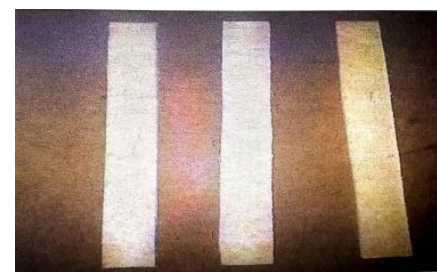

(a) Specimen

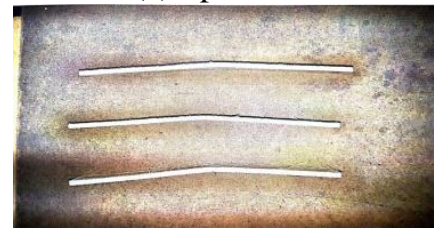

(c) Flexural Test

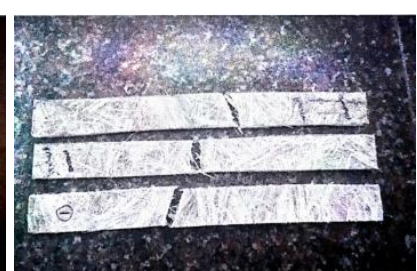

(b) Tensile Test

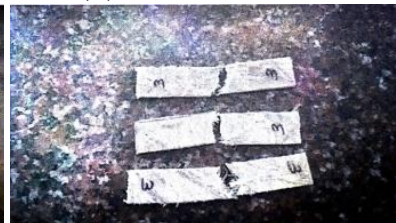

(d) Impact Test
Fig. 4: Tested Specimen after Mechanical test

\section{RESULT AND DISCUSSION}

Polymers are non-natural-reversible material. The researchers come across a serious problem to treat the polymer solid waste. The disposal of the polymer solid waste is not cost effective and subsequently produces more harmful chemicals, Ku et al. (2011). To solve the disposal issue the other way is to increase the durability of a polymer material by reinforcing. Banana Bunch is a waste generated after plucking the fruits. It is a rich in fiber content but it is not effectively used, and it is thrown away for decomposition. In this paper, the mechanical behaviour of composite which is reinforced with Banana bunch fiber in polymer epoxy has been studied. The result of the tensile properties of BFRC and CFRC shows that BFRC performs better at 30 percentage of fiber by weight. The tensile strength of BFRC and CFRC is found to be similar to the physical properties of both materials. Both $\mathrm{BF}$ and $\mathrm{CF}$ have a good surface texture; hence bonding between polymers and natural fibers are good. The result of the flexural properties of BFRC and CFRC shows that BFRC performs better at 40 percentage fiber content as the strength of $\mathrm{BF}$ is

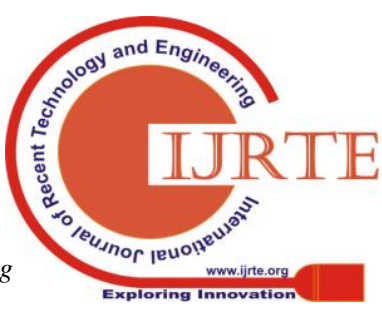


higher. The flexural modulus of BFRC and CFRC has increased with an expanding addition of fiber content, as two materials are high modulus material they demand higher stress for the similar deformation. Utilization of BFRC and CFRC fiber material give outcomes into increment in the modulus of rupture. In which the BFRC performs well in 50 percent replacement of fiber to weight composites. Increment in the percentage of fiber increases the impact strength of BFRC and CFRC. As a good impact resistor BFRC shows that it has a good bonding with the polymer composite; hence it is capable of absorbing more energy. The entangle property of BFRC is excellent due to rough surface texture provides a good grip. The study on mechanical property of BFRC and CFRC shows that BFRC is good lightweight reinforcing material in polymers composites which can be used for suitable application where reinforcement is required.

\section{CONCLUSION}

The mechanical property of Banana Fiber Reinforced Composites (BFRC) and Coconut Fiber Reinforced Composites (CFRC) has been studied. The tensile property of BFRC is found to be similar to CFRC, and both composites are having a tensile strength of $23.78 \mathrm{Mpa}$ and 21.05 Mpa. It is identified that there is good bonding with polymers. The flexural strength test shows that on the addition of fibers BFRC performs well, and with an increment of percentage of fibers increases the flexural modulus. The impact test result shows that BFRC resists more energy at 50 percentages by weight of fibers of 14.47 $\mathrm{KJ} / \mathrm{m} 2$ which is 27.66 percentages higher than the CFRC.The mechanical property of BFRC found to be reasonable when compared to CFRC. In the packaging, transportation interiors, furniture, building construction industry, the BFRC can be used.

\section{REFERENCES}

1. Ahmad I, Baharum A, Abdullah I (2006). "Effect of extrusion rate and fiber loading on mechanical properties of Twaronfiber-thermoplastic natural rubber (TPNR) composites".J ReinfPlast Composite, Vol.25, pp 957-65.

2. Ashok Kumar.M, Ramachandra Reddy.G, HarnathaReddy.G, Chakrdhar.KVP, Nanjunda Reddy.BH and SubramaniReddy.N, (2011). "Mechanical properties of randomly oriented short sansevieriatrifasciatafiber/epoxy composites". International Journal of fiber and Textile Research. Vol 53, No.1, 85-95.

3. Ashok Kumar.M, Ramachandra Reddy.G, Vishnu Mahesh.KR, ThmmapuramHemanthBabu, Vasantha Kumar Reddy.GDasatha.H and MohanaReddy.YV,(2011). " Fabrication and performance of natural fibers: Sinsevieria cylindrical, waste silk, jute and drum stick, vegetable fibers reinforced with rubber/ polyester composites. International Journal of fiber and textile research, Vol. 53, No.1, 15-21. 4. Elanchezhian.C, VijayaRamnath.B, Ramakrishnan.G,
Rajendrakumar.M, Naveenkumar.V, and Saravanakumar.MK, (2018). "Review on mechanical properties of natural fiber composites". Materials Today: Proceedings Vol. 5, No.1, pp 1785-1790.

5. Hameed Sahib Sana and Fahad M.Besma, (2015). "Improve the impact strength of polymer-Polymer composites after post curing". Journal of Modern Engineering Research, Vol.5, No7, pp 40-47.

6. Ku.H, Wang.H, Pattarachaiyakoop.N and Trada.M, (2011). : A review on the tensile properties of natural fiber reinforced polymer composites". Journal of Composites, Vol 42. No.4, pp 856-873.

7. MunikencheGowda.T, Naidu.ACB, Rajput Chaya, (1999). "Some mechanical properties of untreated jute fabric-reinforced polyester composite, Journal of Composites, Vol.30, No.3, pp277-284.

8. N Kistaiah, C Udaya Kiran, G Ramachandra Reddy, M Sreenivasa Rao. "Mechanical characterization of hybrid composites: A review", Journal of Reinforced Plastics and Composites, 2014.
9. Nak-Ho Sung and Nam.P.Suh, (1979). “ Effect of fiber orientation on friction and wear of fiber reinforced polymeric composites". J.Wear, Vol.53, No.1, pp 129-141.

10. Rajesh Egala, SrinivasuGangiSetti. "Impact characterization of epoxy LY556/ricinuscommunis L, plant natural fiber composite materials", Materials Today: Proceedings, 2018

11. Ratna Prasad AV, MohanaRao.K, and Nagasrinivasulsu.G. (2009).“ Mechanical properties of banana-EFB fiber reinforced polyester composites". Indian Journal of Fiber and Textile Research, Vol 34.

12. S.Sivasaravanan, V.K.Bupesh Raja, Manikandan, Impact characterization of Epoxy LY556/E-Glass Fibre/ Nano Clay Hybrid Nano Composite Materials, Procedia Engineering, 2014.

13. Satyanarayana KG, Ravikumar KK, Sukumaran K, Mukherjee PS, Pillai SGK, Kulkarni AG (1986). "Structure and properties of some vegetable fibresTalipot and Palmyrahfibres". J Mater Sci ;21:57-63.

14. Senthilkumar K, I.Siva, N.Rajini and P.Jeyaraj, Effect of fibre length and weight percentage on mechanical properties of shortsisal/polyster composite, International Journal of Computer Aided Engineering and Technology, 2015.

15. Shao-Yun Fu and Bernd Lauke, (1996). "Effects of fiber length orientation distributions on the textile strength of short fiber reinforced polymers". Composite Science and Technology, Vol.56, No.10, pp 1179-1190.

16. Singha AS and Vijay Kumar.T (2008). : Mechanical properties of natural fiber reinforced polymer copmposites, Bulletin of Material Science, Vol.31, No.5, pp 791-799.

17. Wenying Zhou, Calferg Wang, Tao Ai, Ke Wu, Fenjuan Zhao and Hongzhi.Gu, (2009). "A Novel fiber reinforced polyethene composite with added silicon nitride particles for enhanced thermal conductivity". J. Composites: Part A, Vol 40, No.1, 830-836.

18. YozoMikata and Minorutaya, (1985). "Stress field in a coated continuous composite subjected to thermo- Mechanical loadings". Journal of Composites, Vol.19, No.1, pp 554-576.

\section{AUTHORS PROFILE}

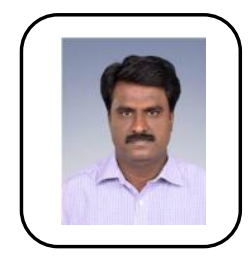

Dr.Muthukannan M completed his Ph.D in Civil Engineering in Anna University, Chennai in the year 2010. He completed Master of Engineering in the field of Transportation Engineering and Management in College of Engineering, Guindy, Chennai in the year 2004. He completed his Bachelor of Engineering under Madurai Kamarajar University in the year 2000. He is presently working as a Professor in Civil Engineering department at Kalasalingam University, Tamilnadu, India. He is guiding for many $\mathrm{Ph} . \mathrm{D}$ scholars in the field of transporation engineering and Geopolymer Technology. He has published various quality papers in the reputed journals. His main thrust research areas are Geopolymer technology, transportation network design, transport management and travel demand management.

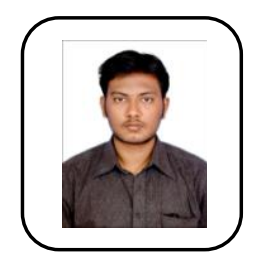

Mr.Chithambar Ganesh. A completed his M.Tech in Structural Engineering in VIT University, Vellore in the year 2015. He completed his Bachelor of Engineering under Anna University in the year 2012 $\mathrm{He}$ is working as Assistant Professor in Department of Civil Engineering at Kalasalingam University, Tamilnadu, India. His main thrust research areas are Geopolymer concrete and Fiber reinforced concrete.

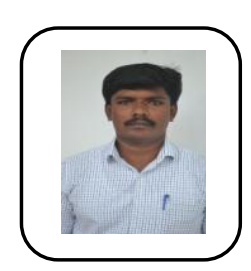

Mr. Mukilan. KMukilan K Completed his Maste of Engineering in the field of Construction Engineering and Management in RVS Technical Campus, Coimbatore in the year of 2015 .He completed his Bachelor of Technology under Kalasalingam University in the year of 2012. He has more than fiveyears of experience in teaching.He has published various papers in the reputed journals. His main thrust research areas are Construction management. 